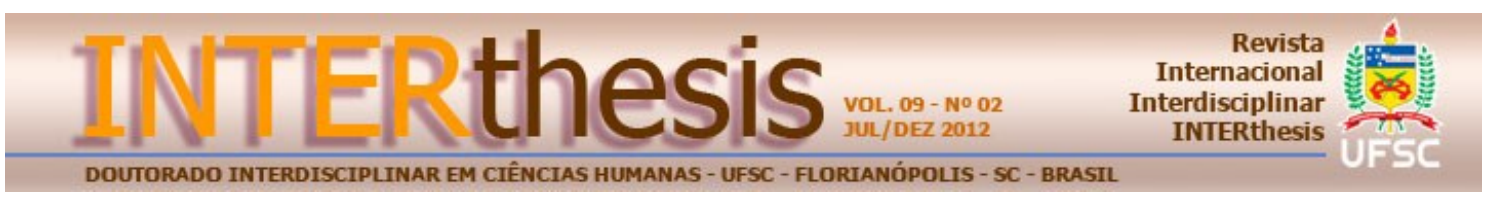

\title{
INTER E/OU TRANSDISCIPLINARIDADE COMO CONDIÇÃO AO ESTUDO DE QUESTÕES SOCIOAMBIENTAIS ${ }^{1}$
}

\section{INTER AND/OR TRANSDISCIPLINARITY AS CONDITION TO THE STUDY OF SOCIOENVIRONMENTAL ISSUES}

\section{INTER YIO TRANSDISCIPLINARIEDAD COMO CONDICIÓN PARA EL ESTUDIO DE CUESTIONES SOCIO-AMBIENTALES}

\author{
Marcelo Gustavo Aguilar Calegare ${ }^{2}$ \\ Nelson da Silva Júnior ${ }^{3}$
}

\section{Resumo:}

O objetivo deste artigo é discutir a necessidade de adotarmos abordagens inter e/ou transdisciplinares para o estudo das questões socioambientais contemporâneas. Por meio das proposições de Fazenda (2007, 2008), Japiassu (2006) e Morin (2008), discutem-se a respeito dos seguintes tópicos: a) a fragmentação disciplinar na consolidação da ciência moderna e a necessidade contemporânea de religação do saber; b) a apresentação de algumas abordagens possíveis da interdisciplinaridade; c) a compreensão da transdisciplinaridade como uma nova maneira de fazer ciência. Sustenta-se a necessidade de adotarmos novos referenciais científicos e, por outro lado, apontarmos alguns desafios para estudarmos questões socioambientais segundo a inter e/ou transdisciplinaridade.
Palavras-chave:
Questões
socioambientais.
Interdisciplinaridade.

Transdisciplinaridade. Ciência.

\begin{abstract}
:
The purpose of this paper is to discuss the need to adopt approaches to inter and/or transdisciplinarity to the study of contemporary socioenvironmental issues. Through the propositions of Fazenda (2007, 2008), Japiassu (2006) and Morin (2008), we discuss the following topics: a) the disciplinary fragmentation in the consolidation of modern science and the contemporary need for reconnection of knowledge; $b$ )

\footnotetext{
${ }^{1}$ Agradecemos à FAPEAM e CNPq pela concessão de bolsa de estudos.

2 Doutor em Psicologia Social pela Universidade de São Paulo (USP). Bolsista do programa de Desenvolvimento Científico Regional (DCR) da FAPEAM / CNPq no Instituto Nacional de Pesquisas da Amazônia (INPA), para pesquisas com comunidades ribeirinhas de Unidade de Conservação. Universidade Federal do Amazonas, Manaus, AM, Brasil. E-mail: mgacalegare@gmail.com

${ }^{3}$ Doutor em Psychopatologie Fondamentale Et Psychanalyse pela Universite de Paris VII - Universitè Denis Diderot. Livre-Docência pela Universidade de São Paulo (USP), Pós-Doutorado - Universitè de Paris VII - Universitè Denis Diderot, Pós-Doutorado pela Universidade Federal de São Paulo (USP). Professor Associado do Instituto de Psicologia da Universidade de São Paulo (USP), São Paulo, SP, Brasil. E-mail: nesi@terra.com.br
} 
presentation of some possible approaches to interdisciplinarity; c) the understanding of transdisciplinarity as a new way of doing science. We argue about the need to adopt new standards of science and, moreover, point out some challenges for studying socioenvironmental issues according to the inter and/or transdisciplinarity.

Keywords: Social-environmental issues. Interdisciplinarity. Transdisciplinarity. Science.

\section{Resumen:}

El objetivo de este artículo es discutir la necesidad de adoptar enfoques inter y/o transdisciplinarios para el estudio de cuestiones socio-ambientales contemporáneas. A través de las propuestas de Fazenda (2007, 2008), Japiassu (2006) y Morin (2008), se discute sobre los siguientes temas: a) la fragmentación disciplinaria en la consolidación de la ciencia moderna y la necesidad contemporánea de reconexión de los conocimientos; b) la presentación de algunos enfoques posibles para la interdisciplinariedad; c) la comprensión de la transdisciplinariedad como una nueva forma de hacer ciencia. Se argumenta sobre la necesidad de adoptar nuevas referencias científicas y, por otro lado, señalar algunos desafíos para el estudio de cuestiones socio-ambientales según la inter y/o transdisciplinariedad.

Palabras clave: Cuestiones socio-ambientales. Interdisciplinariedad. Transdisciplinariedad. Ciencia.

\section{INTRODUÇÃO}

Desde os anos 1970, as autoridades globais vêm tendo a percepção da finitude e destruição do mundo natural, que colocam em risco a existência humana. Beck (1998) nomeia essa conjuntura de "sociedade do risco", isto é, os problemas socioambientais que estão levando a humanidade ao risco da extinção são resultados tanto da geração da riqueza quanto da pobreza, fruto dos processos de modernização e desenvolvimento econômico.

Diegues (2001) define que as questões socioambientais referentes a essa problemática envolvem uma série de fatores: o efeito estufa, a destruição florestal, a perda da bio e sociodiversidade, a poluição de rios e mares, a desertificação crescente, a exaustão de recursos naturais, resultantes de processos que afetam toda biosfera e as sociedades que nelas vivem. Todos esses fatores constituem temas globais, ao lado de outros como a paz, a qualidade de vida, o desenvolvimento etc. Segundo o autor, a globalização das questões socioambientais levou à elaboração de um cenário chamado de "crise ambiental" - posteriormente rebatizada por alguns autores como "crise socioambiental" (TASSARA, 2008). Esta se pauta na degradação planetária do ambiente e recursos naturais, bem como na tomada de consciência universal da gravidade dessa crise, caracterizada como: 
global, acelerada e crescente, irreversível, ameaçadora, causadora de impactos socioculturais e reforçadora das desigualdades sociais e entre nações (DIEGUES, 2001, p. 22-3).

De acordo com Calegare (2010), a maneira como este cenário se desenvolveu, e as possíveis soluções para o mesmo, encontra respaldo em dois tipos de compreensões: 1) durante a modernidade, o Homem relacionou-se de forma agressiva e conquistadora com o mundo natural, o que causou danos profundos ao ambiente. Atualmente, vive-se uma crise não apenas socioambiental, mas da modernidade, superável pela alteração profunda dos paradigmas científicos, do racionalismo moderno, do consumo, da relação Homem/natureza, etc. 2) Os processos de modernização trouxeram benefícios inquestionáveis à humanidade, ao mesmo tempo em que carregaram prejuízos causados por meio das formas de produção e consumo. Cabe à ciência e às novas tecnologias corrigirem tais erros $\mathrm{e}$ auxiliarem para a continuidade do desenvolvimento e progresso da sociedade moderna.

Apesar da diferença em relação à continuidade ou não dos processos de modernização, um dos pontos em comum a essas duas compreensões é o papel delegado à ciência. Na primeira compreensão, observa-se a necessidade de reformulação dos paradigmas científicos como uma das condições para solucionar a crise socioambiental. Na segunda, acredita-se que a ciência, em conformidade com os paradigmas vigentes, necessariamente deve trazer tais soluções. Em ambos os casos, a ciência tem peso fundamental na resolução dos problemas socioambientais.

Cientistas do mundo todo já perceberam que a busca de soluções para esse cenário é possível quando se integram olhares provenientes de diferentes pontos de vista, uma vez que não se trata apenas de uma questão de ordem econômica isolada, ou biológica, social etc. A natureza deste objeto (questão socioambiental) não é captável por uma só disciplina, mas por várias. Como colocado por Japiassu (2006, p. 26), "no domínio das ciências humanas e do meio ambiente, por exemplo, os objetos de pesquisa revelam-se tão complexos que só podem ser tratados e solucionados por uma abordagem multi-, inter- ou transdisciplinar". Dai falarmos em inter e/ou transdisciplinaridade como condição necessária ao estudo das questões socioambientais contemporâneas. 
Com o objetivo de entendermos melhor tal afirmativa, neste artigo nos propomos a discutir mais detalhadamente as considerações de Fazenda (2007, 2008), Japiassu (2006) e Morin (2008) a respeito da seguinte linha argumentativa: a) a fragmentação disciplinar na consolidação da ciência moderna e a necessidade contemporânea de religação do saber; b) algumas abordagens possíveis a respeito da interdisciplinaridade; c) a compreensão de transdisciplinaridade como uma nova maneira de fazer ciência. Pretendemos, com isso, sustentar a necessidade de adotarmos novos referenciais científicos, isto é, a inter e/ou transdisciplinaridade para o estudo das questões socioambientais, visto ser a disciplinaridade limitada para a compreensão da complexidade dos fenômenos contemporâneos envolvendo tal problemática. Por fim, argumentaremos a respeito de alguns desafios a serem superados, para que seja possível compreender as questões socioambientais segundo um ponto de vista mais amplo, fazendo isso segundo as premissas da inter e/ou transdisciplinaridade.

\section{CONSOLIDAÇÃO E CRISE DISCIPLINAR}

Do ponto de vista da ciência moderna, Valade (1999), explorando colocações de Georges Gusdorf, nos explica que a busca pela interdisciplinaridade, mais do que um progresso, é sintoma da patologia de desintegração e especialização em que atualmente se encontra o saber. Se durante a consolidação da ciência moderna essa segmentação foi importante para a demarcação e aprofundamento de unidades particulares do saber, atualmente o olhar fragmentado dificulta percebermos as relações e conexões entre as diferentes unidades. Nesse sentido, a setorização do conhecimento estorva a visão holística sobre o mundo exterior e interior.

Se por um lado a interdisciplinaridade é sintoma de um problema, paradoxalmente por outro ela é solução. Como aponta Ab'saber (2005), ao debater sobre os problemas socioambientais contemporâneos, "hoje em dia, a interdisciplinaridade torna-se um verdadeiro imperativo para a construção de uma sociedade que seja capaz de receber e absorver, em todos seus segmentos, os benefícios e facilidades dessa ciência integrada" (p.24).

A fragmentação do conhecimento em inúmeras disciplinas, que se faz acompanhar da figura do especialista, teve motivos para ter ocorrido dessa maneira. Segundo Linhares (1999), a disciplinarização do saber está diretamente relacionada

R. Inter. Interdisc. INTERthesis, Florianópolis, v.9, n.2, p.216-245, Jul./Dez. 2012 
com o advento da modernidade, na íntima relação com a emergência do capitalismo e industrialização. Segundo a autora,

\begin{abstract}
o projeto de industrialização - fruto da razão e da política hegemônicas na modernidade - não podia prescindir do disciplinamento dos saberes, submetendo-os a um regime severo, que operava no sentido de uma produção que também atingia o corpo, enquadrando-o em tempos e espaços modelados pelos regimes de poder (LINHARES, 1999, p.22).
\end{abstract}

Linhares aponta ainda que houve uma correspondente disciplinarização da sociedade, que produz a disciplinarização dos saberes ao mesmo tempo em que é por eles produzida, submetendo uma "lógica fragmentária e hierárquica a serviço de controladores de mentes e corpos" (LINHARES, 1999, p. 22). Essa racionalidade moderna, em si mesma disjuntiva, avaliza a figura do especialista autorizado a falar a respeito de seu tema, mas que não consegue tecer as conexões que enlaçam a complexidade da sociedade. Para Chaui (2003), trata-se do discurso competente, segundo o qual aqueles que possuem determinados conhecimentos têm direito natural de mandar e comandar os demais em todas as esferas da vida social. Seriam estes os incompetentes, que executam ordens e aceitam os efeitos das ações dos especialistas, mantendo uma estratificação social correspondente àquela dos especialistas. Segundo a autora, a hiperespecialização contemporânea, orientadora de pesquisas e aplicações científicas alimentadas pela necessidade do progresso capitalista, afastou o humano como sentido de sociedade para entronizar a eficácia econômica como centro das justificações sociais.

Como relembra Fazenda (2007), as críticas a respeito da visão restrita de cada disciplina sobre a realidade passam a ser discutidas segundo o crivo da interdisciplinaridade a partir dos anos 1960, na Itália e França. Nesses países viviase um momento em que insurgiam os movimentos estudantis clamando pelo rompimento da lógica instituída até então. Reivindicava-se um novo estatuto de universidade e o rompimento da educação por "migalhas", pois se visualizava o conhecimento sendo reproduzido segundo privilégio de certas ciências, excessiva especialização e que produzia um olhar numa única, restrita e limitada direção. Questionava-se a verdade paradigmática da ciência moderna:

- a razão como critério de conhecimento,

- a lógica formal como sustentáculo da objetividade,

- a dissecação do saber global em partes para melhor estudá-lo,

R. Inter. Interdisc. INTERthesis, Florianópolis, v.9, n.2, p.216-245, Jul./Dez. 2012 
- a experimentação científica para verificação da veracidade de fatos.

Após os questionamentos dos anos 1960, o movimento dos estudiosos a respeito da interdisciplinaridade passou pelas seguintes etapas (divisão didática): anos 1970, sua definição e conceituação; anos 1980, busca de epistemologias e métodos; anos 1990, construção de uma teoria da interdisciplinaridade. Desse percurso enfrentado pelos estudiosos do tema, Fazenda nos mostra que a verdade paradigmática da objetividade vem sendo substituída pelo erro e pela transitoriedade da ciência, o que conduz à superação da dicotomia ciência/existência, separada com o advento do pensamento cartesiano. Como argumenta Morin (2008, p.138),

a separação sujeito/objeto é um dos aspectos essenciais de um paradigma mais geral de separação/redução, pelo qual o pensamento científico ou distingue realidades inseparáveis sem poder encarar sua relação, ou identifica-as por redução da realidade mais complexa a menos complexa.

O autor explica que a ciência moderna se baseou na exclusão do sujeito, conforme a resolução dada por Descartes para o problema filosófico do sujeito: dissociou-se o sujeito (res cogitans), remetido à metafísica (especulação filosófica), e o objeto (res extensa), domínio da ciência. O método cartesiano partia de um princípio simples de verdade, ou seja, que identificava a verdade com as ideias claras e distintas - por isso, simplificação segundo uma visão determinista e unidimensional da realidade. É o que Morin chama de paradigma da simplificação, isto é, o "conjunto dos princípios de inteligibilidade próprios da ciência clássica, e que, ligados uns aos outros, produzem uma concepção simplificadora do universo" (MORIN, 2008, p.330).

A verdade, segundo esse ponto de vista, baseia-se em dados verificados/verificáveis e aptos a fornecer previsões concretas. As certezas do conhecimento científico são obtidas segundo o método experimental, isto é, tomar um objeto e colocá-lo em condições artificiais para tentar controlar as variações nele provocadas. Por esse método, trata-se de encontrar dados concretos, coerentes, matematizáveis, formalizáveis, não falsificáveis, reprodutíveis e concordantes. Isso é o que confere objetividade. A aleatoriedade é desconsiderada em nome de um universo estrito e totalmente determinista. A contradição, ao invés de apontar facetas diferentes de um fenômeno, é sinal de erro. Essa visão de ciência tradicional é reconsiderada ao reponderar-se o erro e a transitoriedade da ciência, pois "a 
verdade da ciência não estava em suas teorias, mas no jogo que permitia a confrontação dessas teorias, no jogo da verdade e do erro; a ciência não possui verdade, mas joga num nível de verdade e de erro" (MORIN, 2008, p.155). Ou seja, verdade científica e erro - o que foge à regra, o imprevisto, o contraditório, as falhas de tradução, o que gera a vida e a morte - caminham juntos na produção da verdade e são considerados segundo o consenso dos cientistas, envolvidos em um contexto. Se toda verdade depende de sua condição de formação ou de existência, isso significa que ela é transitória.

$\mathrm{Na}$ retomada da subjetividade como aspecto central para a construção do conhecimento, Fazenda nos fala de "novas formas de conhecimento - a do conhecimento vivenciado e não apenas refletido, a de um conhecimento percebido, sentido e não apenas pensado" (FAZENDA, 2007, p.115). Para a autora, as dicotomias do paradigma científico tradicional vêm sendo superadas na medida em que começa a aparecer o que chama de uma epistemologia da alteridade, isto é, no momento em que "razão e sentimento se harmonizem, em que objetividade e subjetividade se complementem, em que corpo e intelecto convivam, em que ser e estar co-habitem, em que tempo e espaço se intersubjetivem" (FAZENDA, 2007, p.17, grifo da autora). O que está presente nesse novo ciclo científico

\begin{abstract}
é que a objetividade científica ou verdade reside única e exclusivamente no trabalho da crítica recíproca dos pesquisadores, resultado de uma permanente construção e conquista, de uma teoria que se coloca permanentemente em estado de risco, na qual a regra fundamental metodológica consiste, como diz Japiassu, na imprudência de fazer do erro uma condição essencial para a obtenção da verdade (FAZENDA, 2007, p.42, grifo da autora).
\end{abstract}

Segundo tais colocações, a objetividade de um estudo é garantida perante a atitude do pesquisador na construção do conhecimento: a interdisciplinaridade como processo, como atitude interdisciplinar. Nesse sentido, Fazenda (2007) frisa que é impossível a construção de uma única, absoluta e geral teoria da interdisciplinaridade, mas é necessária a busca ou o desvelamento do percurso teórico pessoal de cada pesquisador que se aventurou a tratar as questões desse tema. Em outras palavras, uma pesquisa de cunho interdisciplinar deve ser compreendida pelo movimento percorrido pelo pesquisador no rompimento das barreiras disciplinares da qual parte, sem com isso deixar de ter em sua disciplina as bases para percorrer esse caminho.

R. Inter. Interdisc. INTERthesis, Florianópolis, v.9, n.2, p.216-245, Jul./Dez. 2012 
Para prosseguir nesse debate, faz-se necessário que tratemos dos distintos agrupamentos disciplinares: multi-, pluri-, inter- e transdisciplinaridade. Para Iribarry (2003), disciplinaridade é a exploração científica e especializada de determinado domínio homogêneo de estudos, com conjunto sistemático e organizado de conhecimentos com características próprias de ensino, formação, métodos e matérias, com a finalidade de fazer surgir novos conhecimentos e substituir os antigos. A disciplina, para Japiassu (2006, p.38, grifo do autor), "enquanto unidade metodológica, é a regra (disciplina) do saber comum a um conjunto de matérias reagrupadas com fins de ensino (discere)". Segundo a definição operacional de disciplinaridade exposta por Iribarry (que iguala ciência a disciplina), podem-se compreender alguns tipos de contatos: multi-, pluri-, inter- e transdisciplinaridade. Vejamos o que se entende por cada um desses agrupamentos.

\section{MULTI E PLURIDISCIPLINARIDADE}

Multidisciplinaridade. Uma gama de disciplinas propostas simultaneamente, sem cooperação entre elas (do ponto de vista disciplinar) e sem fazer aparecer diretamente as relações que podem existir entre elas. Por exemplo, um hospital que possui equipe multidisciplinar: os profissionais não possuem articulação disciplinar (medicina, enfermagem, física, química, psicologia etc.) e trabalham isoladamente (cada um segundo seus métodos), não obstante tenham o objetivo comum de alcançar a saúde dos atendidos. O paciente passa por uma contagem de linfócitos, em seguida é atendido pelo oncologista e, depois, vai à sala de quimioterapia (IRIBARRY, 2003).

Pluridisciplinaridade. Concerne ao estudo de um objeto de uma só e mesma disciplina por várias disciplinas ao mesmo tempo, como exposto por Nicolescu (1996). Por exemplo, a filosofia marxista pode ser estudada pelo olhar cruzado da filosofia com a física, economia, psicanálise ou literatura. No entanto, o aporte das outras disciplinas agrega conteúdo à própria disciplina em foco. No exemplo dado, à filosofia marxista. A abordagem pluridisciplinar alarga as disciplinas, mas sua finalidade permanece inscrita dentro do quadro da pesquisa disciplinar. Japiassu (2006) nomeia esta definição de Nicolescu como multidisciplinar e explica que uma equipe, ao realizar uma pesquisa multidisciplinar, é colocada em cooperação para o 
trabalho e, com isso, pode efetivar-se a troca de saberes. Portanto, já há um avanço da pesquisa mono- à multidisciplinar.

\section{INTERDISCIPLINARIDADE}

Pela raiz etimológica da palavra, interdisciplinaridade significa relação entre disciplinas (YARED, 2008). Para haver entre, é preciso partir da disciplinaridade. Para Miranda (2008, p.113), "a interdisciplinaridade tem se constituído como termo polissêmico de estudos, interpretação e ação", ressaltando que essa característica contribui para sua reflexão e crítica, uma vez que o movimento de acomodação do termo resultaria em sua morte de sentido. De acordo com esse posicionamento de Miranda, a interdisciplinaridade já não se inscreve apenas como atividade cognitiva, mas como ação - o que a coloca num campo que transcende a atividade científica, isto é, a ação segundo o ético e o político.

Ainda a respeito da polissemia comportada pelo termo, Tavares (2008) reforça que um dos principais pressupostos para se caminhar interdisciplinarmente é o diálogo, para se reconhecer aquilo que falta de um lado e que pode ou deve receber do outro. Ou como coloca Japiassu (2006), quebrar o isolamento disciplinar pela negociação de pontos de vista, projetos e interesses divergentes/convergentes, a fim de propiciar:

- a circulação de conceitos e esquemas;

- a emergência de novos esquemas cognitivos e hipóteses explicativas;

- interferências, interfecundações e fusões;

- a constituição de concepções organizadoras que permitam articular o domínio disciplinar num sistema teórico comum.

Por essas colocações, trataremos de apresentar três significados atribuídos à interdisciplinaridade, que servem para reflexão e guia à construção de percurso com ações interdisciplinares.

Como nova inteligibilidade

O primeiro deles, já indicado anteriormente, refere-se à interdisciplinaridade como atitude, o que dá a possibilidade de irmos ao encontro de uma ação 
interdisciplinar. Fazenda (2008) nos diz que a interdisciplinaridade é uma atitude de ousadia e busca frente ao conhecimento. Segundo a autora,

entendemos por atitude interdisciplinar, uma atitude diante de alternativas para conhecer mais e melhor; atitude de esperar ante os atos consumados, atitude de reciprocidade que impele à troca, que impele ao diálogo - ao diálogo com pares idênticos, com pares anônimos ou consigo mesmo atitude de humildade diante da limitação do próprio ser, atitude de perplexidade ante a possibilidade de desvendar novos saberes, atitude de desafio - desafio perante o novo, atitude em redimensionar o velho - atitude de envolvimento e comprometimento com os projetos e com as pessoas neles envolvidas, atitude, pois, de compromisso em construir sempre da melhor forma possível, atitude de responsabilidade, mas, sobretudo, de alegria, de revelação, de encontro, enfim, de vida (FAZENDA, 2007, p.82).

Em outras palavras, a busca de novas formas de acesso à realidade, de inteligibilidade, em que as noções de parte e todo adquirem abordagens distintas. Isso só é possível quando submetido a um tratamento eminentemente pragmático, em que "a ação passa a ser o ponto de convergência e partida entre o fazer e o pensar da interdisciplinaridade" (FAZENDA, 2007, p.67). Nessa mesma linha argumentativa, Japiassu (2006) reforça que a atitude interdisciplinar deve resultar de um trabalho perseverante de sínteses imaginativas bastante corajosas, sem ter a ilusão de que basta a simples colocação em contato dos cientistas de disciplinas diferentes para se criar a interdisciplinaridade.

A atitude interdisciplinar é ação não apenas como categoria, mas como investigação epistemológica (natureza, fonte e validade do conhecimento), ontológica (o que é o ser, em sua essência, e como constrói o conhecimento) e axiológica (o componente valorativo inerente a cada área do saber). É transgressora à medida que questiona as formas estabelecidas e enraizadas da realidade, contextualizada social, econômica e politicamente, sem com isso deixar de agir nesta mesma realidade textual/contextual. Nesse sentido, a atitude interdisciplinar recoloca aos cientistas a questão da objetividade/subjetividade na produção do conhecimento. Segundo Miranda (2008, p.119-120),

ao revelarmos a interdisciplinaridade como atitude, esta nos convoca a refletir sobre as possibilidades de uma ação que promova a parceria e a integração, e este movimento implica o difícil exercício do conhecer-se, porque impõe uma ação paradoxal de busca e posicionamento das questões existenciais, na tentativa de compreensão da relação entre os acontecimentos percebidos e seus reflexos no eu interior e, ainda, como devolvo tudo isso aos outros e à vida externa. 
Por essas colocações, compreendemos que o diálogo entre os envolvidos na construção coletiva do conhecimento não abarca apenas as externalidades das palavras, mas também aspectos da interioridade, que nos trazem indícios valiosos advindos da interação com pessoas, ambientes e situações. O mesmo questionamento a respeito da realidade exterior vale para a interior, o que nos faz ter muita atenção e cautela a respeito da validade daquilo que consideramos como informação e conhecimento das experiências vividas e registradas. Por isso, o trabalho de registro, reflexão e diálogo é essencial para a pesquisa interdisciplinar, por possibilitar o trânsito de significados e o estabelecimento de acordos entre estes.

Para Japiassu (2006), temos de superar o medo advindo da separação sujeito/objeto de considerar que nossa subjetividade não faz parte dos objetos. Muito pelo contrário, sempre estamos fazendo traduções da realidade, o que mostra que toda leitura é subjetiva, como enfatiza Morin (2008). Isso envolve erros. Como já dito, os erros são condição da verdade. A verdade é constituída pelos acordos, consensos e diálogos, que segundo esta acepção de interdisciplinaridade devem ser reflexivos, críticos, entusiásticos, respeitadores e transformadores.

\section{Como interseção metodológica}

O segundo significado atribuído à interdisciplinaridade concerne à transferência de métodos de uma disciplina às outras. Os graus de interdisciplinaridade, segundo Nicolescu (1996), podem ser distinguidos em função do:

- grau de aplicação - da física nuclear, a medicina desenvolve novos tratamentos para o câncer.

- grau epistemológico - a lógica formal inspira análises interessantes na epistemologia do direito.

- grau de engendramento de novas disciplinas - a matemática no domínio da física engendra a física matemática, a física das partículas na astrofísica engendra a cosmologia quântica, etc.

De acordo com Nicolescu, a interdisciplinaridade alarga as disciplinas, mas sua finalidade também permanece inscrita na pesquisa disciplinar.

No que diz respeito às questões socioambientais, foi colocado que a compreensão por uma única disciplina não consegue apreender a complexidade

R. Inter. Interdisc. INTERthesis, Florianópolis, v.9, n.2, p.216-245, Jul./Dez. 2012 
dessa problemática. Uma série de estudiosos, a partir de suas disciplinas, buscou explorar as interfaces e pontos em comum com outros campos, na tentativa de compreender a relação Homem/natureza, subjacente à discussão a respeito da problemática socioambiental. Begossi (2004) e Diegues (2000; 2001; 2004a; 2004b) nos dão um panorama sobre as novas disciplinas, áreas de estudo, movimentos e conceitos oriundos dessas hibridizações que visam compreender a relação da humanidade com os recursos, incluindo aspectos cognitivos, comportamentais e de conservação: Ecologia Profunda, Ecologia Social, Ecossocialismo/ Ecomarxismo, Biologia da Conservação, Ecologia Cultural, Ecologia Humana, Etnociências (com todas suas variações), Sociobiologia, Psicologia Evolutiva, Economia Ecológica, Antropologia Ecológica, Antropologia Neomarxista (ou Econômica).

E mencionamos também: a Psicologia Ambiental, que trata do relacionamento recíproco entre comportamento e ambiente físico, tanto construído quanto natural. E a Psicologia Socioambiental, uma reconsideração da Psicologia Social lewiniana, como proposto por Tassara (2006). Entre muitas outras interseções existentes que não citamos e das quais ainda não temos conhecimento, tamanha difusão no presente.

Como sugere Diegues (2000), pelas teorizações feitas por essa série de (re) agrupamentos disciplinares, também se fazem releituras e propostas de novos conceitos e noções na tentativa de superar o reducionismo biológico (todos os aspectos da vida humana podem ser explicados por fatores biológicos, hereditários etc.) e o reducionismo sociológico (a natureza só é compreensível pelo viés de suas representações culturais). Ou, em outra linguagem, superar a ruptura e oposição entre culturalismo (primazia da cultura, história e sociedade sobre a natureza) e naturalismo (primazia da natureza sobre o Homem e oposta à visão antropocêntrica do mundo) (DIEGUES, 2004b).

Entre essas novas releituras e conceitos estão: coevolução da natureza e cultura, novo naturalismo, etnoconservação, ecologia da paisagem, biodiversidade como fenômeno natural e cultural, manejo como prática cultural de conservação, respeito à diversidade cultural e democracia (DIEGUES, 2000, p.22-40). Como aponta Diegues (2004a), esses conceitos e noções têm orientado cientistas sociais, cientistas naturais, associações locais, organizações não governamentais e técnicos governamentais a tentarem construir novas práticas e ciência da conservação mais apropriadas às condições ecológicas e culturais dos países do Sul.

R. Inter. Interdisc. INTERthesis, Florianópolis, v.9, n.2, p.216-245, Jul./Dez. 2012 
Como intercâmbio de saberes

O terceiro significado de interdisciplinaridade é aquele que busca integrar os conhecimentos de povos e comunidades tradicionais (definidos segundo Decreto 6040/2007) à ciência ocidental, considerando tais saberes como se fossem também uma maneira científica de ordenar, classificar e agir sobre o mundo - por isso, interdisciplinaridade.

Seguindo a esteira de Lévi-Strauss, Diegues (2004a) argumenta que o Homem neolítico já usava de técnicas de cultivo e domesticação oriundas de observação ativa e metódica, com hipóteses ousadas e controladas para serem rejeitadas ou aprovadas por experiências empíricas. Igualmente, povos e comunidades tradicionais se utilizam de técnicas que são: acumuladas durante longo período de tempo; transmitidas oralmente e pela prática; empíricas, por serem constantemente retestadas; e dinâmicas, por se transformarem em função das mudanças socioeconômicas, tecnológicas e físicas. Em suma, a diferença entre o conhecimento tradicional e a ciência seria mais de grau (quantitativo) do que de tipo (qualitativo), por compartilhar da vontade de saber científico, ser capaz de realizar experimentos controlados, quantificar fenômenos e usar métodos elaborados de interferência e reflexão.

Desse modo, a interdisciplinaridade acontece na aliança de cientistas com povos e comunidades tradicionais, em que ambos se unem para compreender e interferir em um determinado objeto: o mar, o manejo da pesca, a conservação de determinada área etc. Um exemplo dessa coordenação de conhecimentos comuns já vem sendo sistematizada também em novos campos disciplinares, além dos já citados, como por exemplo a Antropologia Marítima (ou Socioantropologia Marítima). Esta se constitui como uma subdisciplina da Antropologia, em que a gente do mar, com sua variedade e complexidade dos sistemas técnicos, sociais e simbólicos, é alvo dos estudos antropológicos e de outras áreas, mas é o mar o elemento articulador e de convergência entre os diferentes conhecimentos (DIEGUES, 2004a).

Segundo a argumentação exposta até este momento, podemos compreender a interdisciplinaridade segundo três maneiras: 
1) uma nova inteligibilidade, que requer o rompimento com a racionalidade da ciência moderna e o modo científico padronizado de conhecer - o que exige uma atitude diferenciada;

2) interseção metodológica de disciplinas segundo seus diferentes graus;

3) intercâmbio de saberes da ciência moderna com conhecimentos tradicionais.

As três, a seu modo, implicam na reconsideração do pesquisador sobre seu modo de conhecer e como chegar a determinadas verdades.

\section{TRANSDISCIPLINARIDADE}

Segundo Nicolescu (1996), transdisciplinaridade concerne, como o prefixo trans indica, ao que está ao mesmo tempo entre, através e além das disciplinas. Para Fazenda (2008, p.26), "quem habita o território da interdisciplinaridade não pode prescindir dos estudos transdisciplinares". Isso porque, como descrito por Morin (2008) e Japiassu (2006), os estudos e pesquisas a respeito da transdisciplinaridade antecedem os da interdisciplinaridade. Segundo Morin (2008, p.135, grifo do autor),

o desenvolvimento da ciência ocidental desde o século XVII não foi apenas disciplinar, mas também um desenvolvimento transdisciplinar. Há que dizer não só as ciências, mas também 'a' ciência, porque há uma unidade de método, certo número de postulados implícitos em todas as disciplinas, como o postulado da objetividade, a eliminação da questão do sujeito, a utilização das matemáticas como linguagem e um modo de explicação comum, a procura da formalização, etc. A ciência nunca teria sido ciência se não tivesse sido transdisciplinar.

Por tais colocações, vemos que a transdisciplinaridade busca a unidade do conhecimento. No caso da ciência moderna, esses princípios de unidade, como a matematização e formalização, foram os que enclausuraram as disciplinas - por serem unidades hiperabstratas e hiperformalizadas que tornaram 0 real unidimensional. Atualmente, a transdisciplinaridade busca a unidade não pela redução do real a uma leitura, mas pelo diálogo possível entre diferentes dimensões da realidade. Por esse motivo, parte-se da disciplinaridade para compreender a realidade, mas não se restringe a essa.

R. Inter. Interdisc. INTERthesis, Florianópolis, v.9, n.2, p.216-245, Jul./Dez. 2012 
Por que a busca da unidade no presente? Uma pergunta que parece de ordem metafísica, mística ou religiosa. Para Japiassu (2006, p.73),

\begin{abstract}
numa sociedade em mutação acelerada como a nossa, onde o Homem perdeu quase todos os seus referenciais, todos acreditam que a questão da unidade precisa ser posta, notadamente porque somos obrigados a enfrentar, de um lado, a ultra-especialização dos saberes, do outro, a desagregação dos vínculos sociais e 'políticos' em favor dos neotribalismos conduzindo a uma atomização de nossos conhecimentos e da identidade humana. Enquanto a dispersão e a especialização dos saberes foram decisivas para a fragmentação de nossos conhecimentos; enquanto a racionalidade filosófica e científica, a poesia e a experiência mística parecem tão separadas em domínios irredutíveis e opostos, indispensável se torna a instauração de uma abordagem transdisciplinar tentando reglobalizar nossos saberes e promover, não somente uma unidade essencial do ser humano, mas do mundo onde vivemos.
\end{abstract}

Esse panorama indica que a busca de uma nova transdisciplinaridade, que supere a primeira tentativa da ciência moderna, pode possibilitar a superação da patologia que se encontra o saber atualmente, como nomeia Japiassu.

Quais os princípios dessa nova transdisciplinaridade? Nicolescu (1996) diz que no pensamento clássico não há nada no espaço entre e através das disciplinas, e nem mesmo fora de cada um dos fragmentos que compõem a imagem da pirâmide do conhecimento. Mesmo com o big bang disciplinar, a pirâmide é inteira e setorizada. A perspectiva transdisciplinar pode ser considerada segundo três pilares:

1) há vários níveis de realidade, que se configura como um espaço de descontinuidade e, por isso, todo conhecimento é complementar - e não fragmentado e num só nível da realidade;

2) a lógica do terceiro incluído, em que proposições contrárias podem ser simultaneamente verdadeiras. Pela lei do terceiro excluído temos: ou A é $x$ ou é y, e não há terceira possibilidade. Pela compreensão transdisciplinar, essa terceira possibilidade rompe com o pensamento dualista e permite captar níveis da realidade excluídos pelo pensamento clássico;

3) o mundo presente é impossível de ser inscrito dentro dos parâmetros de uma só disciplina, sendo necessária a compreensão da "complexidade" para captar as intra-, inter- e trans-relações entre os vários níveis da realidade - a unidade plural do conhecimento.

Vejamos esquematicamente o que Morin (2008) explica sobre algumas "avenidas" que conduzem à compreensão do que é a complexidade: 
- a irredutibilidade do acaso e da desordem;

- transgressão da abstração universalista que elimina singularidade, localidade e temporalidade;

- a complicação, em que fenômenos apresentam incalculáveis interações e inter-retroações;

- a misteriosa relação complementar e antagonista de ordem, desordem e organização;

- a organização, que "é aquilo que constitui um sistema a partir de elementos diferentes; portanto, ela constitui, ao mesmo tempo, uma unidade e uma multiplicidade" (MORIN, 2008, p.180);

- o princípio hologramático: "holograma é a imagem física cujas qualidades de relevo, de cor e de presença são devidas ao fato de cada um dos seus pontos incluírem quase toda a informação do conjunto que ele representa" (MORIN, 2008, p.181). E o princípio da organização recursiva, que "é a organização cujos efeitos e produtos são necessários a sua própria causação e a sua própria produção" (p.182);

- a crise de conceitos fechados e claros, isto é, que clareza e distinção são os únicos sinais de verdade;

- a volta do observador na observação, do conceptor na concepção, do diálogo com a contradição, a incerteza, o irracional e o erro para alcançar uma verdade, do pensamento dialógico.

O pensamento dialógico deve ser entendido como pensamento em que duas lógicas, dois princípios, estão unidos sem que a dualidade se perca nessa unidade. Por exemplo, o homem é totalmente biológico e totalmente cultural ao mesmo tempo.

A Carta da Transdisciplinaridade (CIRET, 1994), em seus 14 artigos, explica: é complementar à abordagem disciplinar, por possibilitar a emergência do confronto de disciplinas a novos dados que as articulam entre si e abertura para tudo aquilo que as ultrapassa e atravessa, o que enriquece a leitura da natureza e da realidade. É multirreferencial e multidimensional. Reconhece a existência de vários níveis da realidade. Tenta conciliar a visão das várias ciências, filosofia, arte, literatura e poesia. Leva atitude aberta em relação aos mitos e religião. Baseia-se no diálogo e discussão, seja de origem ideológica, religiosa, política ou filosófica. Não privilegia 
apenas a abstração, mas também o papel da intuição, imaginário, sensibilidade e do corpo na transmissão do conhecimento e ensina a contextualizar, concretizar e globalizar. Tem no rigor, abertura e tolerância suas características fundamentais, isto é:

o rigor na argumentação, levando em conta todos os dados, é a proteção contra desvios possíveis. A abertura comporta a aceitação do desconhecido, do inesperado e do imprevisível. A tolerância é o reconhecimento do direito às ideias e verdades contrárias às nossas (artigo 14 , grifo do autor).

Segundo a argumentação de D'Ambrosio (1997, p. 79-80),

o essencial da transdisciplinaridade reside na postura de reconhecimento de que não há espaço nem tempo culturais privilegiados que permitam julgar e hierarquizar como mais corretos - ou mais certos ou mais verdadeiros - os diversos complexos de explicações e de convivência com a realidade. A transdisciplinaridade repousa sobre uma atitude aberta, de respeito mútuo e mesmo de humildade com relação a mitos, religiões e sistemas de explicações e de conhecimentos, rejeitando qualquer tipo de arrogância ou prepotência.

O autor esclarece que cada cultura construiu seus conhecimentos a partir das particularidades do contexto natural, social e de valores. Isso repercutiu em saberes que aliam teoria e prática que não apenas explicam o mundo, como também fornecem respostas pragmáticas para lidar com as situações geradas pela necessidade de sobrevivência e transcendência. Portanto, a transdisciplinaridade busca colocar em diálogo saberes advindos de distintas fontes, sejam eles provenientes dos cientistas ou de povos e comunidades das mais diversas culturas. Nesse sentido, Santos (2008) relembra que a ciência moderna ocidental se tornou hegemônica ao longo dos últimos séculos, mas que nos últimos anos vêm ocorrendo movimento de revalorização da diversidade e pluralidade epistemológicas. A primeira se refere ao fato de que há diversos modos de conceber o mundo e de intervir sobre ele para conhecê-lo, conservá-lo e transformá-lo, expressos em mitos, saberes e senso comum dos diversos povos. A segunda trata da abertura de novos modos de conhecimentos e formas de relacionamentos entre essas diversas ciências. Isso significa que se pode considerar que a transdisciplinaridade é transcultural em sua essência (D'AMBROSIO, 1997).

Em argumentação semelhante e diretamente relacionada com as questões socioambientais, Leff (2002) aponta que "a problemática ambiental ultrapassou o 
campo dos paradigmas científicos e do conhecimento disciplinar" (p. 176), apesar de exigir integração de conhecimentos, retotalização do saber, aproximações sistêmicas, holísticas e interdisciplinares. Disso resulta que as questões socioambientais requerem novos conhecimentos teóricos e práticos para sua compreensão e resolução, sendo uma dessas respostas o diálogo de saberes. Segundo Leff (2010, p. 95, grifo do autor), "os saberes locais e o diálogo de saberes inscrevem-se na configuração teórica e nas estratégias de construção de uma racionalidade ambiental". Nessa linha, desloca-se a supremacia do conhecimento científico e de sua racionalidade subjacente, para colocar em destaque os saberes locais, que estão arraigados nas condições ecológicas de desenvolvimento das culturas, no sentido existencial do ser cultural e nas formas de habitar o território. Como expõe Leff (2012), o saber ambiental reconhece os saberes tradicionais, as identidades dos povos e suas cosmologias como elementos que compõem a forma cultural de apropriação do patrimônio de recursos naturais. A relevância disso repousa no fato de que

o diálogo de saberes abre, assim, uma nova perspectiva para compreender e construir um mundo global - outro mundo possível - fundamentado na diversidade cultural, na coevolução das culturas em relação com seus territórios biodiversos, em uma proliferação do ser e em uma convivência na diferença (LEFF, 2010, p. 96).

Tal qual vimos argumentando, esse diálogo só é possível quando considerado dentro da perspectiva da inter e/ou transdisciplinaridade. Se adotarmos a perspectiva da interdisciplinaridade exposta acima, o diálogo entre saberes acontece pelo intercâmbio entre cientistas e povos e comunidades tradicionais, considerando-se que tais conhecimentos foram adquiridos segundo parâmetros semelhantes de ordenação, classificação e atuação sobre o mundo. É possível estabelecer relações graças aos princípios comuns da produção do saber. Sob a ótica da transdisciplinaridade, o diálogo de saberes ocorre porque a racionalidade científica é incapaz de desvelar inúmeras facetas da realidade. Portanto, é necessário validar outras formas de conhecer (diversidade epistemológica) e correlacionar conhecimentos (pluralidade epistemológica) segundo uma nova racionalidade - a razão aberta de Morin (2008) ou a racionalidade ambiental de Leff (2002, 2010, 2012) - capaz de apreender a complexa realidade. Isso só é possível 
segundo uma forma inovadora de conceber a produção do saber, isto é, pelos princípios da transdisciplinaridade.

Por fim, para Japiassu (2006), a transdisciplinaridade é um objetivo utópico ainda não concretizável, pois um paradigma de unificação dos saberes ainda não está constituído enquanto tal. Por isso o autor chama-a de sonho transdisciplinar, por pretender ser "um meio de compensar as lacunas de um pensamento científico mutilado pela especialização e exigindo a restauração de um pensamento globalizante em busca da unidade, por mais utópica que possa parecer" (p.17). Segundo o mesmo, já somos capazes de formular questões transdisciplinares, tal como os problemas complexos e globais da humanidade, a ecologia, a energia etc., mas sem ainda termos condições de encontrar respostas ou soluções transdisciplinares.

\section{INTER E/OU TRANSDISCIPLINARIDADE EM QUESTÕES SOCIOAMBIENTAIS}

Até o momento, explicamos as compreensões teóricas de alguns autores a respeito da inter e transdisciplinaridade, mostrando que estas estão relacionadas com tentativas de superação da incompletude da ciência moderna por novos paradigmas. Também apontamos que a necessidade de adoção de novos pontos de vista científicos tem como um dos impulsionadores a crise socioambiental contemporânea. Resta-nos, portanto, abordar alguns exemplos práticos da inter e/ou transdisciplinaridade para os estudos de questões socioambientais, para demonstrar como sua adoção vem ao encontro da busca de resolução da problemática socioambiental.

Já argumentamos anteriormente que novas teorias e conceitos emergiram na tentativa de superar a cisão Homem/natureza e, desse modo, favoreceram a elaboração de novas práticas de conservação ambiental, apropriadas ao contexto ecológico e cultural local - especialmente dos países do Sul. Disso resultaram as ideias da etnoconservação, que desponta como uma proposta concreta de união de saberes científicos e tradicionais, com o escopo de aliar conhecimentos para preservação do ambiente e bem-estar da população residente de áreas protegidas. Mais adiante exploraremos melhor o caso da etnoconservação.

Apontamos também que o diálogo de saberes se configura como uma importante chave para a resolução dos problemas socioambientais, por se pautar R. Inter. Interdisc. INTERthesis, Florianópolis, v.9, n.2, p.216-245, Jul./Dez. 2012 
numa racionalidade diferente, pela qual podem emergir novos princípios teóricos e meios instrumentais para orientar o manejo produtivo da natureza. Como indica Leff (2012, p. 57, grifo do autor), "a crise ambiental é uma crise de civilização produzida pelo desconhecimento do conhecimento", sendo necessária uma nova racionalidade subjacente a uma nova ciência para alcançar-se a sustentabilidade.

Em relação à educação para um futuro sustentável, Morin (2000) aponta que esta só é viável caso seja uma educação integral do ser humano, dirigida à compreensão da totalidade e não de componentes setorizados do indivíduo, sociedade e espécie. $\mathrm{O}$ autor aponta, então, sete saberes necessários à educação do futuro: 1) as cegueiras do conhecimento: o erro e a ilusão; 2) os princípios do conhecimento pertinente; 3) ensinar a condição humana; 4) ensinar a identidade terrena; 5) enfrentar as incertezas; 6) ensinar a compreensão; 7) a ética do gênero humano. Todos esses saberes estão pautados no pensamento complexo e na transdisciplinaridade, que questionam a racionalidade científica vigente e se propõem a edificar novas formas de conceber e construir o conhecimento, para vivermos num planeta sustentável.

Um exemplo é dado por Higuchi, Lemos e Santos (2007), que explanam que o ensino de ciências no contexto escolar já não pode estar pautado em conceitos tradicionais científicos, por serem estes pouco eficientes e incompletos em muitos aspectos da realidade. Em função disso, o desafio de ensinar às novas gerações o cuidado com a natureza e como abordá-la precisa ser respondido por métodos e conceitos inovadores, que alarguem o entendimento desse ensino. Os autores apresentam um exemplo de horticultura escolar, em que a transdisciplinaridade se mostra como abordagem necessária para recolocar a relação pessoa-ambiente aos alunos. Tal experiência proporciona a compreensão dos ciclos ecológicos das plantas, o cuidado com a terra e a integração com as necessidades humanas, o que faz despertar a consciência de interdependência entre todos esses elementos.

Mais outros exemplos são descritos por Silva e Hainard (2005), para quem o ambiente não é restrito ao domínio das ciências naturais, e sim compreendido como as "relações que os seres humanos mantêm com seus contextos naturais e sociais" (p. 29). Dentro desse ponto de vista, os autores ilustram o caso do consumo doméstico de energia, que vem crescendo a cada ano no mundo todo. O estudo dessa questão só pode ser realizado segundo a interdisciplinaridade, pois não se trata apenas de focar a dimensão da produção de energia por novas matrizes. Trata-

R. Inter. Interdisc. INTERthesis, Florianópolis, v.9, n.2, p.216-245, Jul./Dez. 2012 
se também de relacioná-la aos aspectos ligados ao consumo, às demandas e às necessidades dos usuários. Há distintas dimensões culturais e sociais envolvidas nos processos de consumo e que, direta e indiretamente, interferem consideravelmente no ambiente. Isso indica que

\begin{abstract}
o estudo dos modos de consumo focado em suas consequências no ambiente é, portanto, necessário tanto para elaborar e colocar em marcha as políticas em matéria de energia, de consumo doméstico corrente e de proteção ambiental quanto para informar, sensibilizar e orientar o consumidor em suas práticas em direção à coerência e mesmo para que se possam imaginar novos dispositivos técnicos (SILVA; HAINARD, 2005, p. 45).
\end{abstract}

Os autores expõem também o caso do papel da mulher nos processos de decisão e gestão em ambientes urbanos, que exige também uma perspectiva interdisciplinar. Há grandes desafios sociais e ambientais a serem enfrentados nas cidades, a saber: a densidade das áreas construídas, a gestão da mobilidade, a produção de efeitos nocivos, a qualidade do ar, a poluição sonora, o acesso à água tratada, a evacuação e tratamento das águas usadas, a gestão dos dejetos, a vivência de homens e mulheres em lugares saudáveis etc. Isso tudo gera problema resultantes tanto de representações como de práticas coletivas. Essas múltiplas dimensões do ambiente urbano costumam ser abordadas sem levar em conta as desigualdades entre os gêneros. Portanto, o planejamento, execução e funcionamento de políticas urbanas e ambientais têm como requisito a consideração da diferença de perspectiva entre homens e mulheres, que entendem de maneiras distintas a orientação urbanística e as necessidades pessoais e domésticas. Desse modo, os problemas ambientais urbanos, sob o crivo da noção de gênero, apontam a necessidade de "uma abordagem transversal das práticas sociais, acerca dos problemas do cotidiano, da gestão de conflitos e, finalmente, das dificuldades de acesso às decisões e à definição das escolhas políticas" (SILVA; HAINARD, 2005, p. 82).

Também para Turra (2008) o ambiente é uma dimensão humana e social, por isso a abordagem deve ser socioambiental. Desse modo, as questões socioambientais da atualidade indicam para a possibilidade da transdisciplinaridade, "porque há questões que não foram contempladas pelas ciências, questões que, por novas, exigem outro pensar e outros instrumentos" (p.62). Um exemplo dado pela autora é do crescimento da população mundial, que se revela um fato biológico,

R. Inter. Interdisc. INTERthesis, Florianópolis, v.9, n.2, p.216-245, Jul./Dez. 2012 
cultural, geográfico, técnico e político ao mesmo tempo. Isso implica em sérias questões de distribuição espacial dos contingentes populacionais nas diferentes regiões do planeta, em fluxos de migração, em desigualdades sociais, em pressões sobre os recursos naturais decorrentes das diferentes dinâmicas econômicas, em crescimento da produção, em adensamentos urbanos (verticalização e periferização), entre muitos outros fatores. Em suma, o conhecimento disciplinar é explicitamente insuficiente para abordar essa problemática.

Bettine (2008) também argumenta que a complexidade dos problemas ambientais requer novos conhecimentos teóricos e práticos para a resolução de problemas concretos, apontando para a transdisciplinaridade como caminho para tal. A autora mostra que as ideologias teóricas e os paradigmas científicos tradicionais dificultam a reorientação de práticas produtivas para o desenvolvimento sustentável, complementando que

o saber que se busca constituir é o da interação homem-ambiente, permitindo que as ações antrópicas sobre o ambiente, que visam ao bemestar humano, possam não exaurir os recursos disponíveis nem causar impactos ambientais e, ainda, que possam estabelecer ações compensatórias de mitigação (BETTINE, 2008, p.75).

Essa abordagem da autora, focada em práticas produtivas, problematiza questões pragmáticas como a gestão dos recursos hídricos. No caso do uso da água, estão envolvidos fatores como: finalidade de seu uso (industrial, agrícola e de infraestrutura social), qualidade e quantidade disponíveis nos mananciais, atores sociais envolvidos (identidades culturais, qualidade de vida e consumo), valores de uso (fatores econômicos), recuperação e manutenção da qualidade da água, recuperação de áreas vegetadas, estabelecimento de práticas de manejo da bacia, programas de educação ambiental para redução do consumo, tecnologias para diminuição do desperdício, alternativas técnicas de reutilização. Isso demonstra que, além do conhecimento técnico de processos de engenharia hidráulica e química, devem-se reconhecer os hábitos de consumo, causas de esgotamento do meio biofísico e saberes da população envolvida em toda essa cadeia. Além desse exemplo, a autora ainda cita a geração e destinação de resíduos sólidos, a produção e consumo de energia, a ocupação e uso do solo, que mostram que os problemas ambientais atuais exigem práticas transdisciplinares. 
Por fim, Matallo Jr. (2008) descreve o fenômeno da desertificação - definida como a degradação da terra nas zonas áridas, semiáridas e subúmidas decorrente de fatores como a variação climática e as atividades humanas -, que vem se agravando de modo alarmante nos últimos anos e é um caso concreto de transdisciplinaridade. A ampliação desse conceito, para além dos três eixos estruturantes (degradação da terra, variações climáticas, atividades humanas), pode ser definida como "uma área fisicamente degradada e socialmente desestruturada" (p.94). Portanto, a abordagem transdisciplinar é necessária para compreender não apenas temas relacionados ao clima, solo, água e vegetação, mas também às ações humanas que causam esse fenômeno e que geram profundas mudanças sociais, econômicas e culturais. Dessas causas - o socialmente desestruturada -, o autor explana que as zonas áridas do mundo concentram grande contingente populacional, caracterizados por atividades e modos de vida tradicionais. Com a crescente integração das zonas semiáridas marginais ao mercado, tais segmentos sociais passaram a sofrer pressão e influência para adoção de novos processos produtivos. Isso resultou, ao longo dos anos, num processo de degradação ambiental por intensificação e manejo inadequado dos recursos naturais, gerando consequentemente mudanças drásticas na estrutura social e familiar (migrações, abandono da terra, dissolução da unidade produtiva familiar etc.). Esse cenário mostra que a leitura e a solução desse problema complexo, segundo o autor, só podem ser alcançadas no âmbito da transdisciplinaridade.

Esses distintos exemplos mostram que a complexidade dos problemas socioambientais exige novas abordagens científicas, uma vez que aquelas vigentes não são suficientes para resolvê-los. Trata-se não apenas de formas de leitura mais apropriadas para uma realidade complexa, mas da busca de soluções para remediar e reverter o cenário atual e para dar novo direcionamento às futuras gerações.

\section{CONCLUSÃO}

A busca da transdisciplinaridade aparece como uma "necessidade histórica de se promover uma reconciliação entre sujeito e objeto, entre homem exterior e interior, e de uma tentativa de recomposição dos diferentes fragmentos do conhecimento" (JAPIASSU, 2006, p. 40). Nesse sentido, as atitudes do pesquisador que se inspira no sonho transdisciplinar são idênticas àqueles já descritas a respeito

R. Inter. Interdisc. INTERthesis, Florianópolis, v.9, n.2, p.216-245, Jul./Dez. 2012 
da atitude interdisciplinar, por se tratar da superação de obstáculos oriundos de uma aprendizagem disciplinar arraigada em princípios unidimensionalizantes.

Desse modo, o primeiro desafio para empreendermos estudos das questões socioambientais pautados numa abordagem inter e/ou transdisciplinar concerne à postura do pesquisador. Como coloca Morin (2008), trata-se de atitude de coragem para romper com o instituído. Aventurar-se e ser criativo, abrir diálogo com a irracionalidade, o místico, o religioso, o misterioso, a desordem, o incerto, o inesperado, o acaso, o antagonista, o contraditório, o erro.

Um exemplo claro para ilustrar esse primeiro desafio é aquele dado por Diegues (2000), ao propor a etnoconservação como uma nova abordagem para preservação da natureza. Segundo o autor, os cientistas naturais possuem uma compreensão do que é o mundo natural e como ele deve ser preservado. Cientistas sociais costumam ter uma abordagem diferente, enfocando-se mais nas produções simbólicas dos seres humanos a respeito do ambiente. E os povos locais que habitam as florestas há muitos anos, por exemplo, também possuem uma compreensão distinta do que é a vida e a natureza, expressando conhecimentos por meio de mitos e de práticas cotidianas. A etnoconservação só é possível à medida que distintas visões de mundo são colocadas lado a lado, com igual peso e sem discriminação do valor do conhecimento, para um mesmo objetivo: a manutenção de uma área natural, considerando-se que esta se concretiza graças às pessoas que ali habitam, que a significam e que, por suas práticas, mantêm-na viva. Essa abertura para o diálogo de saberes entre diferentes atores envolve, necessariamente, a atitude que descrevemos como um primeiro desafio.

Um segundo desafio refere-se aos métodos, que como vimos estão arraigado nas bases disciplinares, mas que podem seguir princípios da transdisciplinaridade. Nesse sentido, Morin (2008) aponta que não existe uma metodologia da complexidade, apesar de podermos construir um método pautado em seus princípios. Segundo o autor, devemos renunciar ao mito da elucidação total do universo, não obstante precisamos prosseguir na aventura de conhecê-lo. Isso indica a eleição de estratégias, definidas como "a arte de utilizar as informações que aparecem na ação, de integrá-las, de formular esquemas de ação e de estar apto para reunir o máximo de certezas para enfrentar a incerteza" (MORIN, 2008, p.192). Portanto, não temos métodos inter e/ou transdisciplinares, mas podemos traçar estratégias condizentes com uma nova atitude científica.

R. Inter. Interdisc. INTERthesis, Florianópolis, v.9, n.2, p.216-245, Jul./Dez. 2012 
Em outras palavras, podemos pensar nos conceitos sem dá-los por concluídos, quebrar esferas fechadas e restabelecer articulações do que foi separado, a fim de compreendermos a multidimensionalidade da realidade, a singularidade com a localidade e temporalidade. Trata-se da busca pela totalidade integradora de antagonismos, sem apagá-los. Com isso, a complexidade tem alguns imperativos: a) o uso estratégico da dialógica, isto é, duas lógicas ao mesmo tempo. b) o pensar de forma organizacional, ou seja, a relação auto-eco-organizadora, que significa a relação íntima e profunda com o ambiente, a relação hologramática e a recursividade (MORIN, 2008, p.192-3).

Um exemplo que ilustra este segundo desafio nos é dado por Calegare (2010), ao indicar como as crenças de curandeiros de comunidades ribeirinhas amazônicas contêm conhecimentos valiosos à cura dos doentes dessas localidades. A utilização dessas práticas tradicionais pode trazer benefícios à população local por meio de trabalhos de recuperação e valorização não só desses conhecimentos, mas do modo de vida de seus habitantes. Isso só é possível com o estabelecimento de estratégias dialógicas, em que se reconhece que tais práticas tradicionais são conhecimentos tão valiosos quanto aquele oriundo das práticas médicas ocidentais. $\mathrm{O}$ autor nos mostra que em localidades onde foram recuperadas, valorizadas e sistematizadas práticas de cura tradicional, a procura por postos de saúde diminuiu $\mathrm{e}$, além disso, houve aumento no sentimento de pertencimento à comunidade $\mathrm{e}$ estima da floresta.

Por fim, um terceiro desafio é o rompimento dos domínios de uma disciplina a respeito de algum tema em questão, para ampliá-lo segundo novas abordagens. Por exemplo, não é possível entendermos a exaustão dos recursos naturais apenas pelo viés da Economia, com fórmulas de adequação de extração de matéria prima e consumo. Silva (2009) nos dá o exemplo da Economia Ecológica, fundada no princípio de que o sistema econômico é um subsistema dentro do ecossistema biofísico global, pois é deste que derivam a energia e matérias-prima para o próprio funcionamento da Economia. Portanto, para compreendermos essa dinâmica de inter-relações entre ambiente, sistema econômico e necessidades humanas, é necessário adotarmos pontos de vista que integrem os conhecimentos de diferentes disciplinas. Esse é um desafio de formação dos cientistas, como ressalta Japiassu (2006), uma vez que é na academia que a visão unidimensionalizante da ciência moderna é ensinada.

R. Inter. Interdisc. INTERthesis, Florianópolis, v.9, n.2, p.216-245, Jul./Dez. 2012 
Segundo o autor, é imprescindível que nos centros universitários existam programas de pesquisa voltados à formação de cientistas com bases numa nova maneira de se produzir conhecimento. Para chegar a tal objetivo, trata-se não apenas de estabelecer grupos interdisciplinares apenas no nome, mas de conduzir investigações que agreguem pesquisadores de distintas áreas em projetos conjuntos nas distintas etapas: elaboração das ideias, sistematização da investigação, eleição de métodos, análise dos dados e possíveis intervenções.

Em suma, compreender a complexidade das questões socioambientais exige também a ampliação da maneira como estas são pensadas. A expansão do ponto de vista a respeitos dos problemas socioambientais, segundo argumentamos, passa necessariamente pelo alargamento dos limites disciplinares e das abordagens dos cientistas sobre a realidade. Nesse sentido, os três desafios apenas enunciados acima não exaurem todas as questões envolvendo as premissas da inter e/ou transdisciplinaridade. Não obstante, constituem-se como primeiros grandes obstáculos para termos novas formas de fazer ciência. 


\section{REFERÊNCIAS}

AB'SABER, A. Refletindo sobre questões ambientais: ecologia, psicologia e outras ciências. Psicologia USP, vol. 16, nº 1/2, p.19-34, 2005. Psicologia e Ambiente.

BECK, U. La sociedad del riesgo: hacia una nueva modernidad. Traducción: Jorge Navarro, Daniel Jiménez, Ma. Rosa Borrás. Barcelona: Paidós, 1998.

BEGOSSI, A. Introdução: Ecologia Humana. In: __ (org.). Ecologia de pescadores da mata atlântica e da Amazônia. São Paulo: Hucitec; NEPAM/UNICAMP; NUPAUB/USP; FAPESP, 2004.

BETTINE, S. C. Desenvolvimento, ambiente e engenharia ambiental. In: PÁDUA, E. M. M.; MATALLO JR., H. (orgs.). Ciências sociais, complexidade e meio ambiente: interfaces e desafios. Campinas, SP: Papirus, 2008.

CAlegare, M. G. A. Contribuições da Psicologia Social ao estudo de uma comunidade ribeirinha no Alto Solimões: redes comunitárias e identidades coletivas. 2010. 322p. Tese (doutorado). Instituto de Psicologia da Universidade de São Paulo, São Paulo, 2010.

CENTRE INTERNACIONAL DE RECHERCHE ET ETUDES TRANSDISCIPLINAIRES - CIRET (1994). Carta da Transdisciplinaridade. Primeiro congresso mundial da transdisciplinaridade. Arrabida, Portugal. Disponível em: <http://basarab.nicolescu.perso.sfr.fr/ciret/index.htm>. Acessado em: 03 de Ago, 2010.

CHAUI, M. S. Cultura e democracia: o discurso competente e outras falas. $10^{\mathrm{a}}$ Edição. São Paulo: Cortez, 2003.

D'AMBROSIO, U. Transdisciplinaridade. $2^{\mathrm{a}}$ Edição. São Paulo: Palas Athenas, 1997.

DIEGUES, A. C. S. Etnoconservação da natureza: enfoques alternativos. In: (org.). Etnoconservação: novos rumos para a proteção da natureza nos trópicos. São Paulo: NUPAUB/USP; Annablume; Hucitec, 2000.

Ecologia humana e planejamento em áreas costeiras. $2^{\mathrm{a}}$ Edição. São Paulo: NUPAUB/USP, 2001.

R. Inter. Interdisc. INTERthesis, Florianópolis, v.9, n.2, p.216-245, Jul./Dez. 2012 
A pesca construindo sociedades: leituras em antropologia marítima e pesqueira. São Paulo: NUPAUB/USP, 2004a.

. O mito moderno da natureza intocada. $5^{a}$ Edição. São Paulo: Hucitec; NUPAUB/USP, 2004b.

FAZENDA, I. C. A. Interdisciplinaridade: história, teoria e pesquisa. $14^{a}$ Edição. Campinas: Papirus, 2007.

Interdisciplinaridade-transdisciplinaridade: visões culturais e epistemológicas. In: (org.). 0 que é interdisciplinaridade? São Paulo: Cortez, 2008.

HIGUCHI, M. I. G.; LEMOS, S. M.; SANTOS, C. H. F. Transdisciplinaridade no ensino de ciências. Revista Tempo e Ciência, Manaus: CEULM-ULBRA, nº 14, p.413, 2007.

IRIBARRY, I. N. Aproximações sobre transdisciplinaridade: algumas linhas históricas, fundamentos e princípios aplicados ao trabalho de equipe. Psicologia: Reflexão e Crítica, vol. 16, nº 3, p.483-490, 2003.

JAPIASSU, H. O sonho transdisciplinar: e as razões da filosofia. Rio de Janeiro: Imago, 2006.

LEFF, E. Epistemologia Ambiental. Tradução de Sandra Valenzuela. $2^{a}$ Edição. São Paulo: Cortez, 2002.

Cortez, 2010.

Discursos sustentáveis. Tradução de Silvana Cobucci Leite. São Paulo:

Aventuras da epistemologia ambiental: da articulação das ciências ao diálogo de saberes. Tradução de Silvana Cobucci Leite. São Paulo: Cortez, 2012.

LINHARES, C. Memórias e projetos nos percursos interdisciplinares e transdisciplinares. In: FAZENDA, I. C. A. A virtude da força nas práticas interdisciplinares. $1^{\text {a }}$ Edição. Campinas: Papirus, 1999. 
MATALLO JR., H. Sociedade e meio ambiente: o fenômeno da desertificação como um caso concreto de transdisciplinaridade. In: PÁDUA, E. M. M.; MATALLO JR., H. (orgs.). Ciências sociais, complexidade e meio ambiente: interfaces e desafios. Campinas, SP: Papirus, 2008.

MIRANDA, R. G. Da interdisciplinaridade. In: FAZENDA, I. C. A. (org.). O que é interdisciplinaridade? São Paulo: Cortez, 2008.

MORIN, E. Os sete saberes necessários à educação do futuro. Tradução de Catarina Eleonora F. da Silva e Jeanne Sawaya. São Paulo: Cortez; Brasília, DF: UNESCO, 2000.

Ciência com consciência. Tradução de Maria D. Alexandre e Maria Alice Sampaio Dória. Ed. revista modificada pelo autor. $11^{a}$ ed. Rio de Janeiro: Bertrand Brasil, 2008.

NICOLESCU, B. La transdisciplinarité: manifeste. Monaco: Edition du Rocher, 1996. Collection "Transdisciplinarité". Disponível em: <http://basarab.nicolescu.perso.sfr.fr/ciret/vision.htm>. Acesso em: 03 de Ago, 2009.

SANTOS, B. S. A gramática do tempo: para uma nova cultura política. $2^{\text {a }}$ Edição. São Paulo: Cortez, 2008.

SILVA, M. A. Introdução à economia ecológica (a economia na perspectiva ecológica). Manaus, UFAM, julho de 2009. Mini-curso $61^{a}$ Reunião anual da Sociedade Brasileira para o Progresso da Ciência.

SILVA, M. C.; HAINARD, F. O ambiente: uma urgência interdisciplinar. Campinas, SP: Papirus, 2005.

TASSARA, E. T. O. A psicologia social e o enfrentamento da crise ambiental. Texto apresentado em Prova de Erudição para obtenção de título de professora titular junto ao Departamento de Psicologia Social e do Trabalho (PST) do Instituto de Psicologia da USP, em 05/05/2006.

(Org.). Dicionário socioambiental: idéias, definições e conceitos. São Paulo, Faarte, 2008.

TAVARES, D. E. A interdisciplinaridade na contemporaneidade - qual o sentido? In: FAZENDA, I. C. A. (org.). O que é interdisciplinaridade? São Paulo: Cortez, 2008. 
TURRA, J. M. T. Para pensar a vida, nosso meio, nossa época e o conhecimento geográfico. In: PÁDUA, E. M. M.; MATALLO JR., H. (orgs.). Ciências sociais, complexidade e meio ambiente: interfaces e desafios. Campinas, SP: Papirus, 2008.

VALADE, B. Le 'sujet' de l'interdisciplinarité. Sociologie et société, vol. $31, \mathrm{n}^{\circ} 01$, printemps, 1999. Disponível em: <http://id.erudit.org/iderudit/001814ar>. Acesso em: 03 de Ago, 2010.

YARED, I. O que é interdisciplinaridade? In: FAZENDA, I. C. A. (org.). O que é interdisciplinaridade? São Paulo: Cortez, 2008.

Artigo:

Recebido em: Outubro/2011

Aceito em: Setembro/2012 